\title{
Microanálisis filmico y teoría del cine en la alfabetización audiovisual: estrategias didácticas desde y para la práctica docente universitaria
}

\author{
Rocío Betzabeé González de Arce ${ }^{1[}$ \\ Universidad Autónoma Metropolitana- Unidad Xochimilco, México
}

Autor de correspondencia: ${ }^{1}$ chioglezarce@hotmail.com Recibido: 05 de octubre de 2020 Revisado: 23 de octubre de 2020 Aprobado: 24 de enero de 2021 Publicado: 1 de marzo de 2021

\begin{abstract}
Resumen
El presente artículo propone que el análisis de secuencias cinematográficas - microanálisis fílmico- es una herramienta pedagógica efectiva para la enseñanza de la teoría del cine en el ámbito universitario y que tal enseñanza teórica puede ser el primer paso hacia la alfabetización audiovisual de estudiantes de licenciatura y posgrado. A partir del método inductivo propio de la tradición anglosajona analítica, la investigación partió del análisis de múltiples experiencias en el salón de clases para proponer estrategias didácticas para la alfabetización audiovisual a través de la reflexión teórica que el análisis cinematográfico puede detonar. Con fines didácticos, el texto presenta los resultados de la investigación a través de la narración de una clase hipotética que muestra la manera en que las estrategias didácticas diseñadas pueden implementarse en el aula. Esta parte del texto se estructura alrededor del análisis de cinco secuencias que se utilizan para la enseñanza de tres grupos de teorías del cine: (1) realismo, (2) formalismo y constructivismo y (3) neoformalismo, cognitivismo y postestructuralismo. El artículo busca ser una guía para aquellos docentes interesados en impulsar el alfabetismo audiovisual a través del microanálisis fílmico y la teoría del cine.

Palabras clave: análisis de secuencias, teoría del cine, alfabetización audiovisual, microanálisis fílmico, estrategias didácticas
\end{abstract}




\title{
Film microanalysis and film theory in audiovisual literacy: didactic strategies from and for university teaching practices
}

\begin{abstract}
This article proposes that the analysis of film sequences-film microanalysis-is an effective pedagogical tool for teaching film theory at university level and that such theoretical teaching may be the first step towards the audiovisual literacy for undergraduate and postgraduate students. Using the inductive method typical of the Anglo-Saxon analytical tradition, the research was based on the analysis of multiple experiences in the classroom in order to propose didactic strategies for audiovisual literacy through the theoretical reflection that film analysis can trigger. For didactic purposes, the text presents the research results by narrating a hypothetical lesson that shows how the didactic strategies designed could be implemented in the classroom. This section is structured around the analysis of five sequences that are used for the teaching of three groups of film theories: (1) realism, (2) formalism and constructivism, and (3) neoformalism, cognitivism, and post-structuralism. The article aims to be a guide for teachers interested in promoting audiovisual literacy through film microanalysis and film theory.
\end{abstract}

Keywords: sequence analysis, film theory, film literacy, film micro-analysis, didactic strategies

\section{Microanálise de filmes e teoria do cinema na alfabetização audiovisual: estratégias didáticas de e para a prática do ensino universitário}

\section{Resumo}

O artigo propõe que a análise de sequências de filmes - microanálise de filmes - é uma ferramenta pedagógica eficaz para o ensino da teoria do cinema no âmbito universitário e que tal ensino teórico pode ser o primeiro passo para a alfabetização audiovisual de estudantes de graduação e pós-graduação. Com base no método indutivo da tradição analítica anglo-saxônica, a pesquisa teve início a partir da análise de múltiplas experiências em sala de aula para propor estratégias didáticas para a alfabetização audiovisual através da reflexão teórica que a análise cinematográfica pode desencadear. Para fins didáticos, $o$ texto apresenta os resultados da pesquisa através da narração de uma aula hipotética que mostra como as estratégias didáticas projetadas podem ser implementadas na sala de aula. Esta parte do texto é estruturada em torno da análise de cinco sequências que são utilizadas para o ensino de três grupos de teorias cinematográficas: (1) realismo, (2) formalismo e construtivismo e (3) neoformalismo, cognitivismo e pós-estruturalismo. $\mathrm{O}$ artigo pretende ser um guia para os professores interessados em promover a alfabetização audiovisual através da microanálise de filmes e da teoria do cinema.

Palavras-chave: análise de sequências, teoria de filmes, alfabetização cinematográfica, microanálise fílmica, estratégias didáticas 
De acuerdo con Ferrés (2006), la alfabetización audiovisual permite a los individuos desarrollar competencias en comunicación audiovisual, es decir, la capacidad para "interpretar y analizar desde la reflexión crítica las imágenes y los mensajes audiovisuales para expresarse con una mínima corrección en el ámbito comunicativo" (p. 10). En este sentido, el alfabetismo audiovisual es indispensable para asegurar el pleno ejercicio de los derechos a la libertad intelectual y al acceso a la cultura, que la Declaración Universal de los Derechos Humanos de las Naciones Unidas consagra en sus artículos $19^{1}$ (ONU, 1948, p. 6) y $27^{2}$ (p. 8), respectivamente. Sin embargo, ni los programas gubernamentales de cultura ni nuestro sistema educativo consideran la alfabetización audiovisual como parte indispensable de la formación de los habitantes de nuestro país, a pesar de que México ratificó dicha declaración y de que estamos inmersos en una cultura audiovisual que se caracteriza por la multiplicidad y omnipresencia de las pantallas, así como por la diversidad de formatos audiovisuales - películas, programas televisivos, anuncios publicitarios, videoclips- a través de los que recibimos información y nos comunicamos con los demás (Lipovetsky, 2009). Las razones de esto son sin duda complejas y múltiples, pero considero que entre ellas se cuenta la manera en que se ha concebido el cine como un mero entretenimiento cuyos contenidos son accesibles para todos de manera directa, "natural", casi "innata". Si dicha forma de pensar el cine implica que la alfabetización audiovisual no es necesaria, se hace urgente, para revertir esta idea, comenzar a reflexionar en los salones de clase en torno a cómo concebimos el cine y otros productos audiovisuales. Para ello, el análisis de secuencias es una herramienta didáctica fundamental en el aula.

\section{Perspectivas teórico-metodológicas y procedimientos de investigación}

En el presente artículo propongo que el análisis de secuencias cinematográficas es una herramienta que permite la reflexión teórica alrededor de las distintas concepciones del cine y que, por ello, tiene el potencial de detonar el proceso de alfabetización audiovisual en las aulas universitarias, al poner en evidencia que, como cualquier otro texto, una película puede aprender a leerse y escribirse ${ }^{3}$. Así pues, parto del supuesto de que la secuencia es la unidad básica del análisis cinematográfico y de que el análisis de secuencias - que Zunzunegui (1996) denomina microanálisis fílmico - es la base de cualquier proceso de alfabetización audiovisual, tal como sugieren las propuestas de autores como Bordwell y Thompson (1995), Bordwell (1997), Barsam (2010) y Jullier (2019), entre otros.

Desde una perspectiva teórica, este planteamiento se inscribe en lo que D’Agostini (2000) señala como la tradición filosófica analítica, caracterizada por Zavala (2012) como casuística porque, al contrario de la tradición continental, que va de la teoría a la práctica y de la definición al ejemplo, se mueve de la práctica a la teoría y del ejemplo a la definición. $\mathrm{Si}$, generalmente, la teoría del cine se enseña a partir de textos canónicos que se discuten en

$1 \quad$ El artículo 19 de la Declaración Universal sobre los Derechos Humanos de las Naciones Unidas (1948) dice:

Todo individuo tiene derecho a la libertad de opinión y de expresión; este derecho incluye el no ser molestado a causa de sus opiniones,

el de investigar y recibir informaciones y opiniones, y el de difundirlas, sin limitación de fronteras, por cualquier medio de expresión. (p. 6)

2 El artículo 27 dice: “Toda persona tiene derecho a tomar parte libremente en la vida cultural de la comunidad, a gozar de las artes y a participar en el progreso científico y en los beneficios que de él resulten” (p. 8).

3 Este supuesto, que es la base de la alfabetización audiovisual, se desprende de las teorías semióticas del cine que consideran que, en tanto que tejido de signos, la película es un texto. Un par de títulos sugerentes a este respecto son Lire les images de cinéma (Jullier \& Michel, 2007) y How to Read a Film: Movies, Media, and Beyond (Monaco, 2009). 
el salón de clase, sin que, en la mayoría de los casos, se visione ni una sola secuencia, aquí propongo, en cambio, estrategias didácticas que buscan detonar la discusión teórica a partir del visionado y análisis cinematográfico de secuencias en el aula.

En congruencia con la tradición analítica, apliqué en esta investigación un método inductivo (Zavala, 2012) que, al avanzar de lo particular a lo general, me permitió, comenzando con el análisis de mis experiencias frente a grupo - casos- ${ }^{4}$, diseñar un conjunto de estrategias didácticas que, a través del análisis de secuencias, consiguen detonar la reflexión teórica y contribuyen a la alfabetización audiovisual de los alumnos.

Con la intención de que esta investigación sirva como una guía práctica para aquellos profesores universitarios interesados en promover el alfabetismo audiovisual a través del microanálisis fílmico y la teoría del cine, decidí presentar las diferentes estrategias didácticas resultantes de esta investigación, justamente, de manera inductiva: a partir de su implementación en el aula. Es por esta razón que el grueso del cuerpo del artículo está integrado por la narración de una clase hipotética que se estructura en torno a sucesivos avances de lo particular a lo general, es decir, del análisis de una secuencia a la reflexión teórica.

Dividí el texto en tres secciones, cada una correspondiente a un grupo de teorías del cine. La primera de estas secciones se dedica a las teorías realistas que entienden el cine como una ventana metafórica, mientras que la segunda se refiere a las teorías formalistas y constructivistas que lo entienden metafóricamente como un marco ${ }^{5}$. Ambas secciones comparten como estudio de caso una secuencia de la película High Anxiety (Brooks, 1977). La tercera sección revisa, a partir de tres estudios de caso, las teorías neoformalistas, cognitivistas y postestructuralistas que ven el cine como una puerta figurada. Los casos referidos en esta sección son el episodio "Cuervos" de Los sueños de Akira Kurosawa (Kurosawa, 1990), La invención de Hugo (Scorsese, 2011) y Super Fantozzi (Parenti, 1986). La secuencia de persecución de la película La diligencia (Ford, 1939) se analiza a la luz de las teorías del segundo y del tercer grupo.

Ahora bien, seleccioné las secuencias del corpus en función de su utilidad para la enseñanza de los conocimientos esperados que, en este caso, corresponden a diferentes teorías del cine. Por esta razón, todas las secuencias - con excepción de la de La diligencia (1939) - son metaficcionales. Como ficciones autorreferenciales (Zavala, 2004), estas secuencias tematizan el cine y sus condiciones de posibilidad y, al hacerlo, permiten a los alumnos reflexionar sobre distintas concepciones del cine y los planteamientos teóricos a los que dichas concepciones dan origen. Elegí la secuencia de La diligencia (1939), en cambio, porque, al ser un ejemplo de una película clásica, ofrecía las mayores posibilidades didácticas para la enseñanza del análisis formal a través de las convenciones del lenguaje cinematográfico.

En la parte final del texto, discuto y concluyo, respecto a las ventajas didácticas del

\footnotetext{
4 Las estrategias didácticas emanan del análisis de los resultados obtenidos al poner en práctica el análisis de las secuencias del corpus en diferentes grupos de licenciatura y posgrado entre 2016 y 2018: Seminario de Análisis Cinematográfico — dirigido a alumnos de la licenciatura en Historia del Arte y del posgrado en Estudios de Arte de la Universidad Iberoamericana, Ciudad de México- y módulos del Diplomado de Análisis y Teoría Cinematográfica, Ditacine, —dirigido a alumnos de licenciatura y posgrado de la UACM-. Aunque los grupos estuvieron compuestos de alumnos de licenciatura y doctorado, los cursos estaban dirigidos a un público no especializado en cine.

5 Está categorización se hizo con base en los planteamientos de Elsaesser y Hagener (2015).
} 
uso de secuencias frente al uso de filmes completos, la pertinencia del microanálisis para la enseñanza de la teoría del cine y la alfabetización audiovisual y las características y conveniencia de las estrategias didácticas diseñadas.

\section{Estrategias didácticas, teoría del cine y alfabetización audiovisual}

\section{Realismo: el caso de High Anxiety (1977)}

Emplazada en el jardín, la cámara se desplaza lentamente hacia adelante. Se acerca poco a poco a un amplio ventanal mientras se escucha en primer plano sonoro el chirriar de los grillos. La cámara avanza y comienza a distinguirse el interior de un comedor en el que varias personas departen sentadas a la mesa. El sonido de los grillos desaparece y comienza a escucharse el murmullo apagado de la plática de los comensales. La cámara continúa su avance paulatino hacia el ventanal. Entonces, detengo súbitamente la secuencia, volteo a ver a mis alumnos y les pregunto: “QQué creen que pasará ahora? ¿Qué va a hacer la cámara?”. Un par de ellos se apresura a contestar que la cámara entrará a la habitación. Alguien más sugiere que la ventana se abrirá para permitir el paso de la cámara. La mayoría coincide con que la cámara traspasará "mágicamente" el ventanal. Dejo correr la secuencia. La cámara sigue avanzando, pero, en vez de ingresar a la habitación, choca sorpresivamente contra el ventanal. Los vidrios se rompen produciendo un gran estruendo. La cámara se detiene y permanece inmóvil ante los comensales que voltean a mirarla. Se produce un momento "incómodo" entre los personajes, la cámara y el espectador. Finalmente, la cámara retrocede lentamente, apenada, y los comensales desvían la mirada y reanudan la conversación. Todos mis alumnos ríen. Uno de ellos exclama que la escena es “genial". Pero ¿por qué la escena los mueve a risa? ¿Por qué logra sorprenderlos?

Cuando, tras detener la secuencia de High Anxiety (1977) ${ }^{6}$, pido a mis alumnos que predigan lo que hará la cámara a continuación, lo que en realidad les estoy pidiendo es que reflexionen en torno a la manera en que entienden el propio cine. Cuando mis alumnos se hacen conscientes de que esperan que la cámara se comporte como algo inmaterial, capaz de atravesar el ventanal, se abre la posibilidad de discutir en el salón de clase la manera en que el cine clásico nos ha educado audiovisualmente en la transparencia de la cámara, que funciona como un ojo incorpóreo que nos permite mirar el mundo a través de la ventana transparente de la pantalla cinematográfica. La metáfora de la pantalla como ventana que se abre ante nuestros ojos subyace a las teorías realistas miméticas del cine, que consideran la obra fílmica no como una construcción a partir del lenguaje cinematográfico, sino como representación exacta de lo real. Según Elsaesser y Hagener (2015), para estas teorías, la esencia del cine radica en "su habilidad para registrar y reproducir la realidad y sus fenómenos" (pp. 28-29), ya que el espectador es tan solo un testigo pasivo que mira el espacio tridimensional que se abre más allá de la pantalla a través del vidrio invisible de una ventana, cuyo marco se pierde de vista. Desde esta posición de distancia, el espectador está a salvo y es relevado de cualquier compromiso moral hacia lo que mira por la ventana.

El cine como reflejo de la realidad encuentra su fundamento teórico, por ejemplo, en el realismo ontológico de André Bazin, quien plantea que "el cine, antes aún que representar la

6 La secuencia está disponible en el canal de YouTube de ABCine: https://www.youtube.com/watch?v=bI8mjdp3 us\&feature $=$ youtu.be 
realidad, participa de ella hasta el punto de reproducirla en toda su densidad y consistencia" (Casetti, 2010, p. 46) y el realismo funcional de Kracauer (1960), según el cual el cine está "vinculado a la posibilidad del medio de reproducir los perfiles de las cosas y documentar la existencia" (Casetti, 2010, p. 47) 7 .

Esta muy difundida manera de entender el cine ha contribuido de manera indirecta a que no existan programas de alfabetización audiovisual en nuestro país. ¿Por qué aseguro tal cosa? En parte porque, si se presupone que la cámara captura la realidad, sin manipularla, cualquier material audiovisual puede considerarse transparente en términos de su lectura y todo espectador puede acceder a su contenido de manera directa, sin requerir de algún alfabetismo audiovisual. Sin embargo, esto no es cierto en cuanto a lo que ocurre con el cine, la televisión y el video. Para evidenciarlo, tal vez convenga regresar al ejemplo de la secuencia de High Anxiety (1977).

\section{Formalismo y constructivismo: una vez más el caso de High Anxiety (1977)}

En el momento en que en High Anxiety (1977) la cámara impacta con el ventanal, este adquiere presencia para el espectador. Ello pone en evidencia el artificio y, entonces, la ilusión de realidad se resquebraja. Cuando el vidrio invisible se hace añicos, lo que aparece ante el espectador es la materialidad del marco del ventanal. La pantalla deja de ser una ventana invisible que se abre al mundo para convertirse en un cuadro - cinematográficoenmarcado. La presencia de un marco "remarca el contenido de la superficie (opaca) y la naturaleza construida, implicando de manera eficaz su composición y artificialidad" (Elsaesser \& Hagener, 2015, p. 28). Lo que aparecía como realidad se evidencia ahora como una ficción, un constructo.

Cuando el cristal de la ventana se rompe y mis alumnos se hacen conscientes de la cámara, lo que reconocen es la especificidad material del medio. Además, en la secuencia, el que los personajes se sorprendan y miren a la cámara cuando esta se hace visible produce una ruptura de la cuarta pared en que los personajes miran - a través de la cámaradirectamente a los ojos del espectador, quien, a partir de ese momento, toma consciencia del lugar que ocupa frente al constructo de la película. A partir de este distanciamiento brechtiano (Brecht \& Bentley, 1961, p. 130), el espectador deja de ser un testigo pasivo y se convierte en un voyeur implicado moralmente con aquello que mira. Es esto lo que produce el momento incómodo entre los personajes, la cámara - que también parece cobrar consciencia de sí misma e intenta invisibilizarse de nuevo lo antes posible- y mis alumnos que, al ver incumplidas sus expectativas de transparencia, ríen.

La metáfora del cine como marco subyace a las teorías constructivistas y formalistas que consideran que la percepción cotidiana se distingue de la percepción fílmica por "la alteración y manipulación" que el cine hace a través del "montaje, el encuadre o la ausencia de color y diálogo" (Elsaesser \& Hagener, 2015, p. 29), etc., es decir, mediante el lenguaje cinematográfico ${ }^{8}$. Desde esta perspectiva, el cine no refleja la realidad, sino que la construye. Lo que aparece entonces es el cine como ficción, entendida como verdad contextual, y no como falsedad o falsificación de la realidad (Zavala, 2000). Este carácter

\footnotetext{
7 Para profundizar en las teorías realistas del cine ver: Bazin (1990) y Kracauer (1960).

8 Para profundizar en las teorías formalistas y constructivistas, consultar los trabajos de Balász (2013), Arnheim (1986) y Eisenstein (2001).
} 
de constructo ficcional implica que, para ser aprehendido, el contenido implícito de un material audiovisual requiere de competencias lectoras por parte del espectador, es decir, de un cierto grado de alfabetismo audiovisual. Pero ¿por qué aseguro esto?

La idea del cine como marco implica que la forma es el contenido, y viceversa, por lo que para hacer una interpretación del contenido implícito de una película es necesario estudiar su forma. Precisamente, a través de la alfabetización audiovisual, es posible ofrecer al espectador herramientas para analizar la forma fílmica y con ello interpretar subtextualmente los materiales audiovisuales. Un breve ejercicio de análisis que realizo con mis alumnos puede servir para mostrar esto con claridad en el salón de clases.

Para la actividad, propongo al grupo el visionado de una famosa secuencia del western clásico La diligencia (1939) ${ }^{9}$, en la que una partida de apaches ataca un carruaje en el que viaja un grupo de ciudadanos norteamericanos a través del desierto.

\section{Figura 1}

Tamaños de plano.

\section{TAMAÑOS DE PLANO}

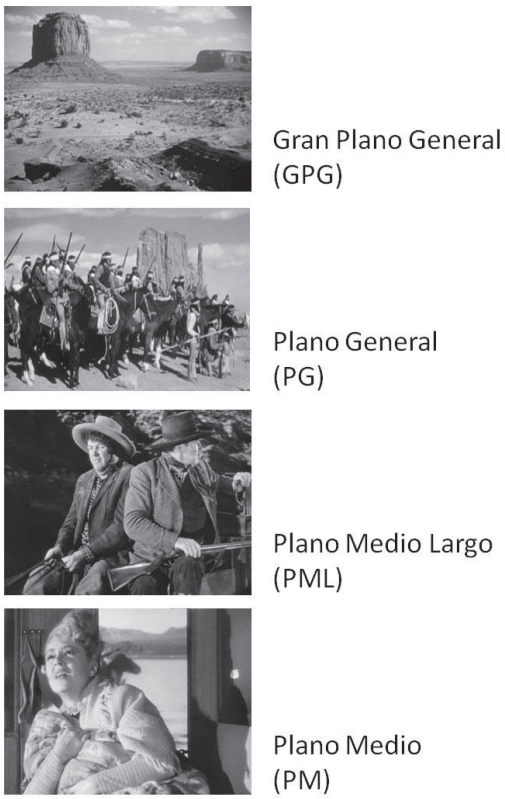

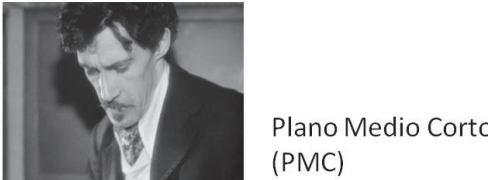

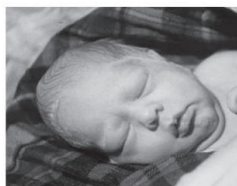

Primer Plano

(PP)

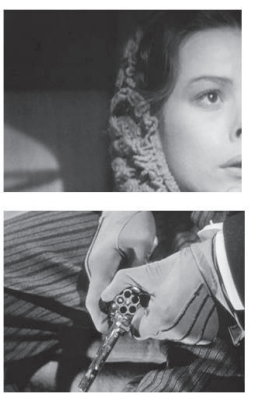

Primerísimo Primer

Plano

(PPP)

Plano Detalle

(PD)

Nota: Elaboración propia a partir de fotogramas de La diligencia (1939) y la tipología del Diccionario Técnico Akal del Cine (Konisberg, 2004).

Antes de mostrarles la secuencia, divido a los alumnos en parejas y les asigno una tarea para realizar durante el visionado. Esta estrategia permite que los alumnos se enfoquen en un aspecto formal de la cinta y desarrollen sus habilidades analíticas. El primer equipo recibe la encomienda de tomar nota del tamaño de plano - abierto, medio o cerrado- con que aparecen los apaches en pantalla. El segundo debe apuntar el tamaño de plano con que se muestra a los pasajeros de la diligencia. El tercero tiene que contabilizar el número de

9 La secuencia de La diligencia (1939) puede visionarse en el canal de YouTube de ABCine: https://www.youtube.com/ watch? $=$ OreGFXJfSE4\&feature=youtu.be 
apaches muertos o heridos durante el enfrentamiento. El cuarto equipo lleva la cuenta de los heridos y muertos de la diligencia. El quinto calcula de manera aproximada la duración promedio - en segundos- de los planos que muestran a los apaches. El sexto estima la duración promedio de los planos que muestran a los pasajeros del carruaje. Al séptimo equipo le corresponde describir la melodía - alegre, triste, amenazante, sombría, etc. - y el tipo de instrumentos que se escuchan cuando aparecen en pantalla los apaches. Finalmente, el octavo debe hacer lo propio con la música que se escucha cuando están a cuadro los pasajeros.

Para realizar el ejercicio es preciso, primero, aclarar al grupo algunos conceptos formales de la imagen cinematográfica. Para ello, repaso con mis alumnos los tamaños de plano que aparecen en la siguiente infografía de la figura 1.

Además, con la figura 2 explico al grupo que los tamaños de plano se definen fundamentalmente por la proximidad de la cámara respecto al sujeto o a los sujetos que filma y que, de acuerdo con ello, los distintos tamaños cumplen diferentes funciones en el cine clásico ${ }^{10}$ (Mascelli, 2012): los planos más abiertos — grandes planos generales y planos generales- suelen ser descriptivos, ya que permiten detallar los espacios y la relación entre personajes; los planos medios - planos medios largos, planos medios y planos medios cortos- suelen ser narrativos, pues permiten seguir acciones en la pantalla; y los planos cerrados - primeros planos y primerísimos primeros planos- suelen ser dramáticos, debido a que expresan las emociones de los personajes.

\section{Figura 2}

Funciones generales de los tamaños de plano

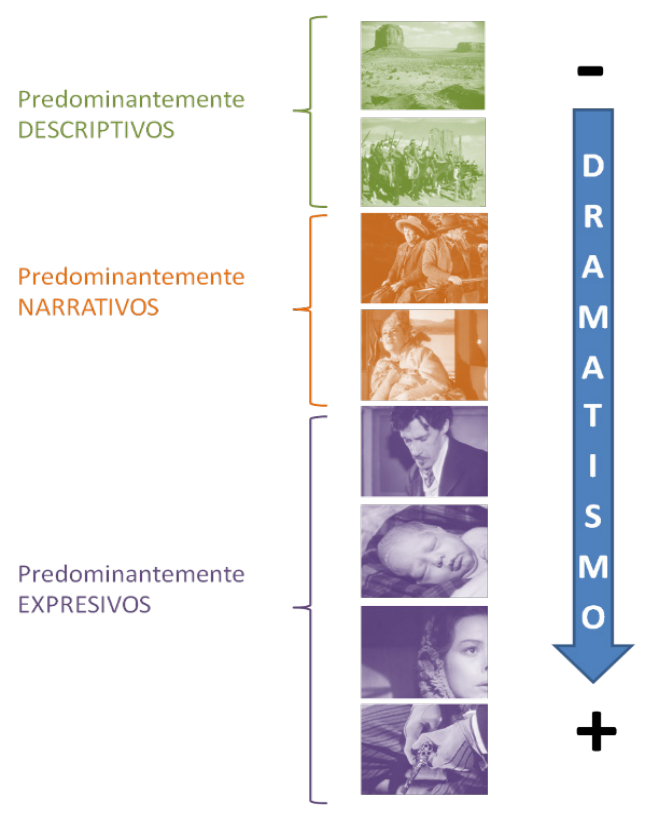

Nota: Elaboración propia con base en (Mascelli, 2012) y con imágenes de La diligencia (1939).

También es fundamental revisar con el grupo la definición de plano: todo aquello que

10 En términos de tamaños de plano y sus funciones, La diligencia (1939) puede considerarse un ejemplo paradigmático del cine clásico de Hollywood. 
en términos de imagen se encuentra entre dos cortes de edición, pues solo a partir de dicha definición los alumnos podrán identificar los distintos planos y calcular su duración promedio.

Una vez revisados estos elementos del lenguaje cinematográfico, proyecto la secuencia de La diligencia (1939) y al finalizar invito a mis alumnos a comentar sus hallazgos a partir de las siguientes preguntas detonadoras:

1. ¿Qué grupo, apaches o pasajeros, ocupa más tiempo en pantalla?

2. ¿Los apaches se muestran en planos mayoritariamente abiertos, medios o cerrados? ¿En qué tamaños de plano se muestra predominantemente a los pasajeros de la diligencia?

3. ¿Cuántos heridos o muertos hubo de cada bando?

4. ¿A quiénes, apaches o pasajeros de la diligencia, se ve caer heridos en planos de mayor fuerza dramática?

5. ¿Qué diferencias en la intensidad — suave o fuerte—, instrumentos utilizados — cuerdas, vientos, percusiones - , tempo — ritmo acelerado o lento- y articulación —notas ligadas o separadas unas de otras- hay entre los motivos musicales que durante los primeros 18 segundos de la secuencia sirven para presentar a los pasajeros y a los apaches, respectivamente?

Los hallazgos reportados por los alumnos pueden discutirse grupalmente a la luz de los resultados que a continuación se presentan:

Respuesta a la pregunta 1. De los 91 planos analizados ${ }^{11}$, más de la mitad - 58-, es decir el $64 \%$, muestran a cuadro exclusivamente a los pasajeros de la diligencia; mientras que 33 -el $36 \%$ - presentan únicamente a los apaches (tabla 1). Ya desde ahí es posible hablar de una mayor exposición en pantalla de los pasajeros de la diligencia respecto a los apaches. Al analizar la duración de cada uno de los 91 planos, dicha inequidad se muestra contundente: mientras los pasajeros están a cuadro durante 5 minutos con 54 segundos, los apaches solo están en campo 2 minutos con 46 segundos.

\section{Tabla 1}

Número y porcentaje de planos abiertos, medios o cerrados que muestran a cuadro exclusivamente a pasajeros de la diligencia o los apaches en la secuencia estudiada de La diligencia (1939)

\begin{tabular}{ccccc}
\hline \multirow{2}{*}{ Grupo de personajes } & \multicolumn{3}{c}{ Tamaño de plano } & \multirow{2}{*}{ Total de planos } \\
\cline { 2 - 4 } & Abierto & Medio & Cerrado & \\
\hline \multirow{2}{*}{ Pasajeros de la diligencia } & 11 & 45 & 2 & 58 \\
& $19 \%$ & $78 \%$ & $3 \%$ & $64 \%$ \\
Apaches & 30 & 2 & 1 & 33 \\
& $91 \%$ & $6 \%$ & $3 \%$ & $36 \%$ \\
\hline \multirow{2}{*}{ Total } & 41 & 47 & 3 & 91 \\
& $45 \%$ & $52 \%$ & $3 \%$ & $100 \%$ \\
\hline
\end{tabular}

11 Si bien la secuencia tiene un total de 106 planos, no se consideran en el conteo final cuatro planos que muestran a cuadro únicamente a la caballería y 11 que son planos compartidos por apaches, pasajeros de la diligencia y/o soldados de la caballería. 
Respuesta a la pregunta 2. Como se muestra en la tabla 1, los pasajeros de la diligencia aparecen mayoritariamente $-78 \%$ de las veces - en planos medios, mientras los apaches aparecen casi siempre - $91 \%$ de las veces - en planos abiertos. Estas diferencias se expresan visualmente de manera más clara en la gráfica 1.

\section{Gráfica 1}

Proporción en la escala de planos de los pasajeros y los apaches en la secuencia estudiada de La diligencia (1939)

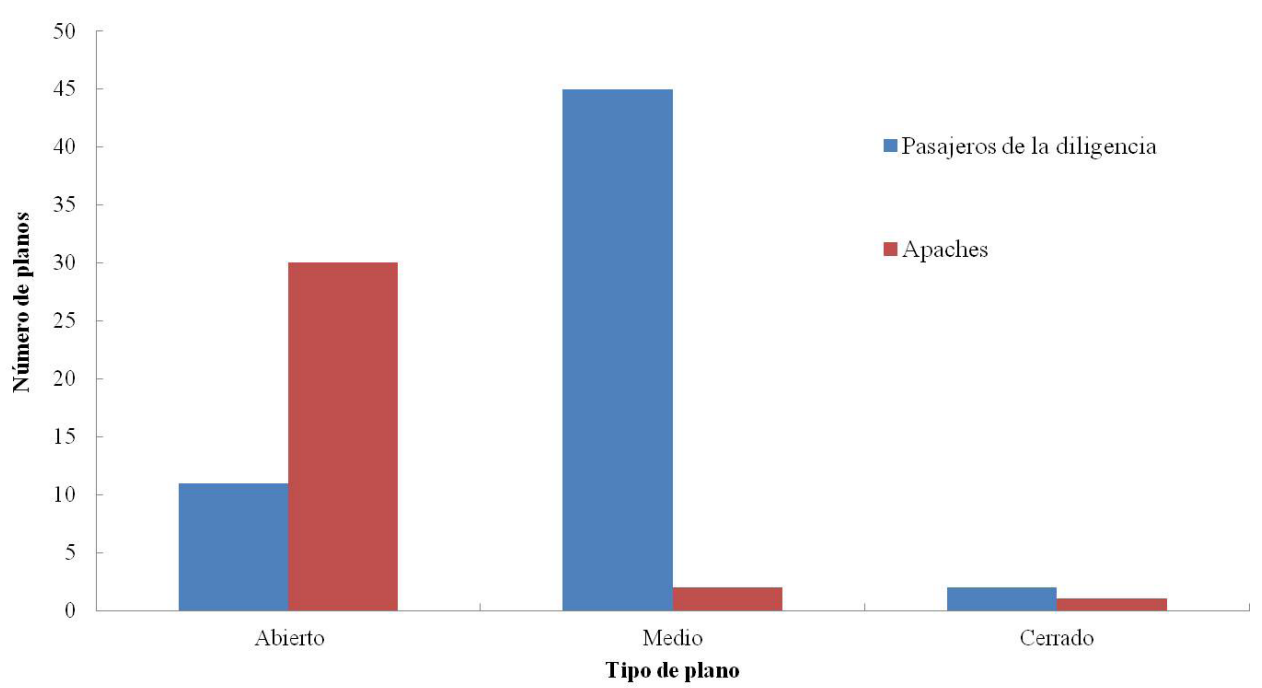

Respuesta a la pregunta 3. El conteo arroja que mientras solo cuatro de los pasajeros fueron heridos - uno de ellos noqueado por otro pasajero-, hubo dieciséis apaches muertos o heridos. Esto se traduce en una relación de cuatro apaches caídos por cada pasajero herido.

Respuesta a la pregunta 4. Como se puede ver en la tabla 2, todos los heridos de la diligencia aparecen en planos medios; mientras que los apaches heridos aparecen en planos abiertos, ya sea en grandes planos generales o planos generales. Esto puede constatarse en los fotogramas de la figura 3, cuya columna izquierda muestra a los pasajeros de la diligencia, mientras que las dos columnas derechas presentan a los apaches. Una revisión de la infografía de la figura 2 permite concluir que los planos medios en que son heridos los pasajeros de la diligencia son más dramáticos que los planos abiertos en los que mueren los apaches.

\section{Tabla 2}

Cantidad de heridos o muertos por parte de pasajeros y apaches y escalas de los planos en los que aparecen en la secuencia estudiada de La diligencia (1939)

\begin{tabular}{ccccc}
\hline \multirow{2}{*}{ No. de plano } & \multicolumn{2}{c}{ Pasajeros de la diligencia } & \multicolumn{2}{c}{ Apaches } \\
\cline { 2 - 5 } & $\begin{array}{c}\text { No. de heridos o } \\
\text { muertos }\end{array}$ & $\begin{array}{c}\text { Tamaño de } \\
\text { plano }\end{array}$ & $\begin{array}{c}\text { No. de heridos o } \\
\text { muertos }\end{array}$ & Tamaño de plano \\
\hline 11 & 1 & medio & - & abierto \\
15 & - & & 2 &
\end{tabular}




\begin{tabular}{ccccc}
26 & - & & 1 & abierto \\
30 & - & 1 & abierto \\
34 & 1 & medio & - & \\
41 & - & 1 & abierto \\
45 & - & 2 & abierto \\
52 & - & 1 & abierto \\
61 & - & 1 & abierto \\
63 & - & 1 & abierto \\
65 & - & 2 & abierto \\
69 & - & 2 & abierto \\
73 & - & & 1 & abierto \\
75 & - & & 1 & abierto \\
78 & 1 & & - & \\
98 & 1 & medio & - & \\
\hline Total & 4 & medio & 16 & \\
\hline
\end{tabular}

Figura 3

Diferencias en los tamaños de plano entre los heridos de la diligencia y los apaches en la secuencia estudiada de La diligencia (1939)

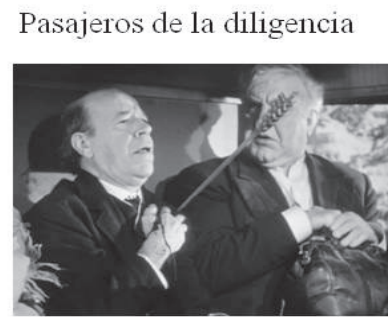

Apaches
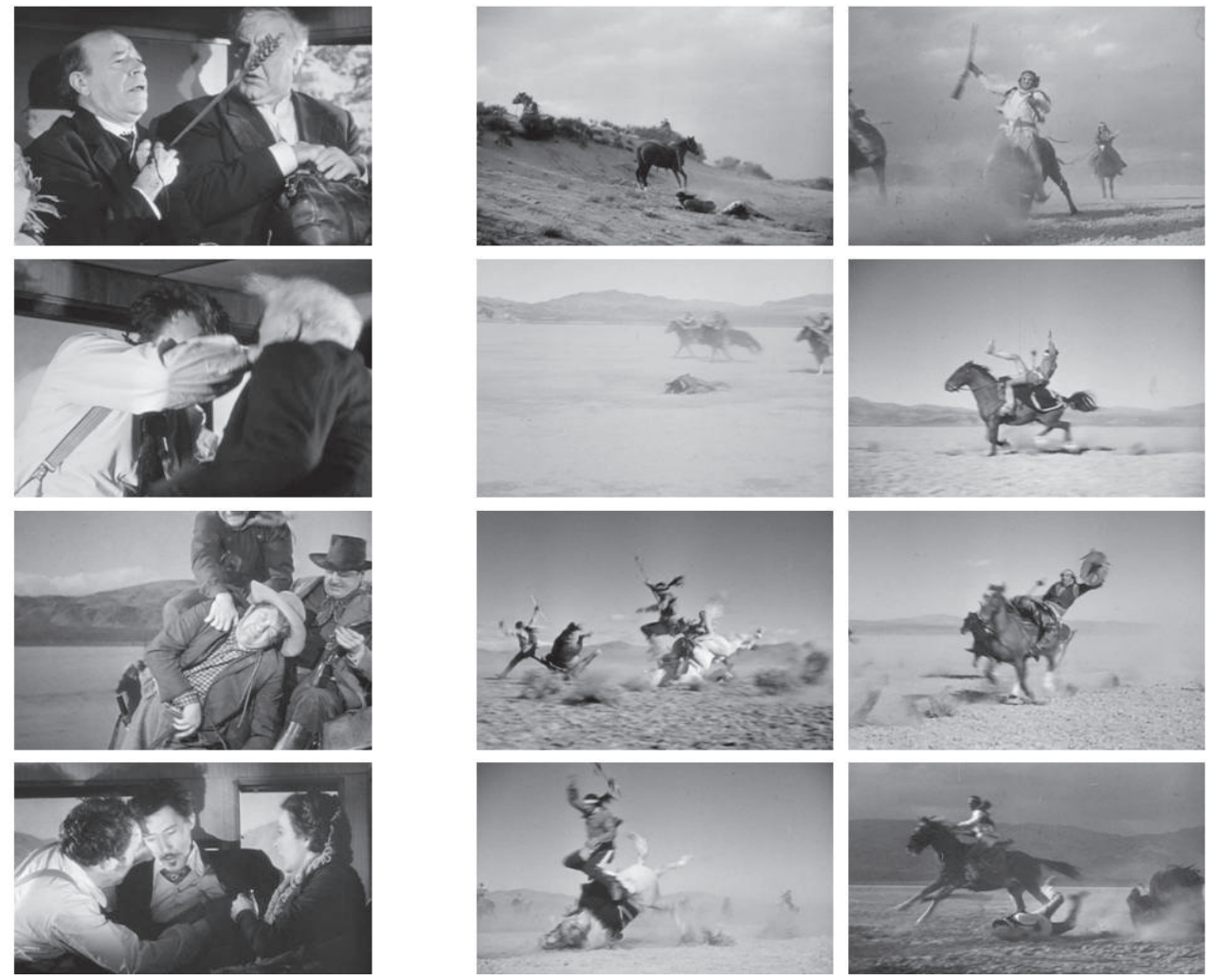

Respuesta a la pregunta 5. Los motivos musicales de los pasajeros y apaches presentan diferencias en intensidad, instrumentación, tempo y articulación. A partir de la descripción de estas características es posible detectar la manera en que los motivos se oponen entre sí. Por un lado, cuando la diligencia aparece en pantalla, al principio de la secuencia, se escucha una melodía suave en la que predominan las cuerdas, pero, cuando los apaches hacen su aparición, la intensidad aumenta y la instrumentación cambia a una combinación 
de percusiones y vientos. Por otra parte, el motivo de la diligencia tiene una métrica $3 / 4$ y un tempo moderato; el de los apaches, en cambio, presenta una métrica $2 / 2$ que comienza accelerando y termina ritardando. Ambos motivos se articulan de manera distinta: el motivo de la diligencia es legato o ligado, pues hay una continuidad entre notas; en cambio, el motivo de los apaches es staccato o picado, pues hay una interrupción total entre una nota y otra.

La discusión grupal de estos resultados corresponde, según Vanoye y Goliot-Lété (2008), solo a la primera fase del análisis cinematográfico, en la que se procede a la deconstrucción de la secuencia estudiada a través de la descripción desglosada y sistemática de los diferentes elementos formales que la componen. Tal descripción se conoce técnicamente como découpage (Burch, 1985). Las tablas y gráficas presentadas hasta aquí pueden considerarse distintas formas de esta técnica, pues presentan de manera sistemática y detallada la descomposición de los elementos formales de la secuencia analizada.

Ahora bien, no basta con discutir grupalmente los resultados del proceso de descomposición de la secuencia. Siempre, según Vanoye y Goliot-Lété (2008), el análisis requiere forzosamente de una segunda fase de reconstrucción que consiste en, a partir de una hipótesis interpretativa, "establecer vínculos entre estos elementos aislados, en entender cómo se asocian y se vuelven cómplices para permitir la aparición de todo un significante" (p. 12). A partir de la reconstrucción de los elementos formales es posible aproximarse al subtexto ideológico o a la visión del mundo subyacente a cualquier filme. Es preciso, entonces, plantear una dinámica que permita al grupo en el aula pasar de la primera a la segunda fase del análisis, es decir, de la descripción a la interpretación.

Aquí proponemos abrir a una discusión grupal las siguientes preguntas para permitir la vinculación entre la descripción formal y la interpretación subtextual:

1. De acuerdo con el número de planos exclusivos y el tiempo en pantalla, ¿cuál es el foco narrativo de la película? (Genette, 1972); es decir, ¿desde la perspectiva de qué bando se cuenta la historia?

2. De acuerdo con el número de heridos o muertos de cada bando y el grado de dramatismo derivado del tamaño de plano, ¿qué muertes son importantes y cuáles no? ¿Cuáles están cargadas de emoción?

3. De acuerdo con el análisis de la música, ¿qué sugieren del carácter moral de los pasajeros de la diligencia y de los apaches la intensidad, la instrumentación, el tempo y la articulación de los motivos musicales con que se les asocia? ¿De qué manera la imagen refuerza o contradice la caracterización que hace la música de cada bando?

En respuesta a estas preguntas es posible decir que:

Respuesta a la pregunta 1. El foco narrativo de la película está en los pasajeros de la diligencia, pues la cámara los acompaña de manera persistente y cercana, mediante muchos planos, largos y cerrados, que permiten al espectador ver sus rostros y, por lo tanto, reconocerlos como individuos y explorar sus reacciones emocionales. Estos recursos formales establecen a los pasajeros como los protagonistas de la película frente al papel secundario que adquieren los apaches, que aparecen en pocos planos, cortos y lejanos. La historia se cuenta desde la perspectiva de los colonizadores y no desde la de los colonizados, lo que implica una postura ideológica colonialista. 
Respuesta a la pregunta 2. El uso de un plano cerrado equivale a poner un acento en aquello que se muestra. Así, cuando un pasajero de la diligencia cae herido en un plano medio, se le agrega importancia al hecho; mientras que cuando dos apaches mueren al mismo tiempo en un gran plano general, se le resta trascendencia al evento. Lo mismo puede decirse de la emoción. Los planos cerrados producen una respuesta emotiva más intensa en el espectador que aquella que producen los planos abiertos. Esto tiene relación con la cercanía virtual con que el espectador experimenta lo que aparece en la pantalla. La cercanía física de la cámara respecto a la acción se traduce, en el cine clásico, en cercanía emocional del espectador con lo que mira. Esto, además, está acentuado por la duración de los planos. Un análisis aún más detallado de la secuencia arroja que los planos cerrados en los que aparecen los pasajeros heridos tienen mucha mayor duración que los brevísimos planos abiertos en los que mueren los apaches. La emoción de los planos cerrados es potenciada por su larga duración. Así pues, podemos concluir que no es lo mismo morir en un plano medio que en un plano general. Lo primero está cargado de dramatismo; lo segundo está desdramatizado y resulta una mera descripción del hecho, desprovista de emoción. Lo que la imagen dice, finalmente, es que hay vidas más importantes que otras y muertes más sentidas que otras. El trasfondo ideológico colonialista de la secuencia es que las vidas de los ciudadanos americanos blancos son más valiosas que las de los habitantes nativos de Norteamérica.

Respuesta a la pregunta 3. Los instrumentos utilizados en los motivos musicales plantean diferencias culturales entre ambos bandos. Los pasajeros se asocian con un instrumento de cuerdas, el violín, que se relaciona con una cultura occidental, de orígenes europeos. Cabe recordar aquí que los primeros colonizadores del norte de América eran ciudadanos ingleses. Los apaches, por su parte, se asocian con instrumentos de viento y percusiones, instrumentos más relacionados étnicamente con las culturas nativas de América. La manera en que se tocan las percusiones, además, resulta un guiño a los tambores que acompañaban las danzas de la guerra que los apaches practicaban como preparación para la batalla.

Además de la oposición cultural planteada por la instrumentación, tanto la intensidad y el tempo como la articulación plantean una oposición moral entre los bandos. La suavidad del motivo de los pasajeros contrasta con la intensidad del motivo apache. Esto sugiere una diferencia de actitud entre grupos: mientras los pasajeros se presentan auralmente como pacíficos, los apaches se presentan como agresivos. Esta diferencia está remarcada por el ritmo más rápido y en aceleración del motivo de los apaches. Además, la métrica del motivo apache -2/2- es comúnmente utilizada en marchas y tiene, por lo tanto, una connotación bélica; en cambio, la métrica -3/4- del motivo de los pasajeros tiene una rítmica valseada que sugiere serenidad. En el motivo de los apaches, las notas son cortas y terminan abruptamente, lo que refuerza la idea de la violencia con la que se les asocia. En el motivo de los pasajeros las notas se prolongan y se coligan unas con otras produciendo un tono más melancólico.

Así, mientras el motivo de la diligencia es apacible y algo taciturno, el segundo resulta amenazante, agresivo y siniestro. Musicalmente los pasajeros son descritos como indefensos; mientras que los apaches son presentados como violentos. Esto, además, está reforzado por la imagen: la diligencia, acompañada de la música apacible, aparece empequeñecida e indefensa en un gran plano general del inmenso desierto, en un plano picado y a merced 
de los apaches, quienes, ubicados en lo alto, ocupan, amenazantes, gran parte del cuadro (figura 4). Los apaches se construyen así, desde la mirada colonialista, como una amenaza sobre los ciudadanos buenos e indefensos.

El ejercicio de análisis que he desarrollado hasta aquí tiene como principio la alfabetización audiovisual, pues parte de la enseñanza de los principios de la forma fílmica y de cómo esta determina el contenido de la película. Ahora bien, la alfabetización audiovisual no solo consiste en proporcionar a los espectadores, a partir del conocimiento y manejo del lenguaje audiovisual, las herramientas necesarias para que desarrollen habilidades críticas que les permitan lecturas múltiples y profundas de los productos audiovisuales que ofrecen el cine, la televisión y la publicidad, sino que también consiste en allegarles los elementos básicos para que, de manera cotidiana, se expresen audiovisualmente, es decir, para que dejen de ser solamente consumidores audiovisuales y se conviertan en productores de sus propios contenidos. De este modo, la alfabetización audiovisual es un proceso que consta de dos fases: la de la lectura interpretativa de lo audiovisual y la de la escritura de lo audiovisual.

\section{Figura 4}

Las imágenes a la izquierda corresponden al motivo musical de la diligencia; las imágenes de la derecha corresponden al motivo musical de los apaches
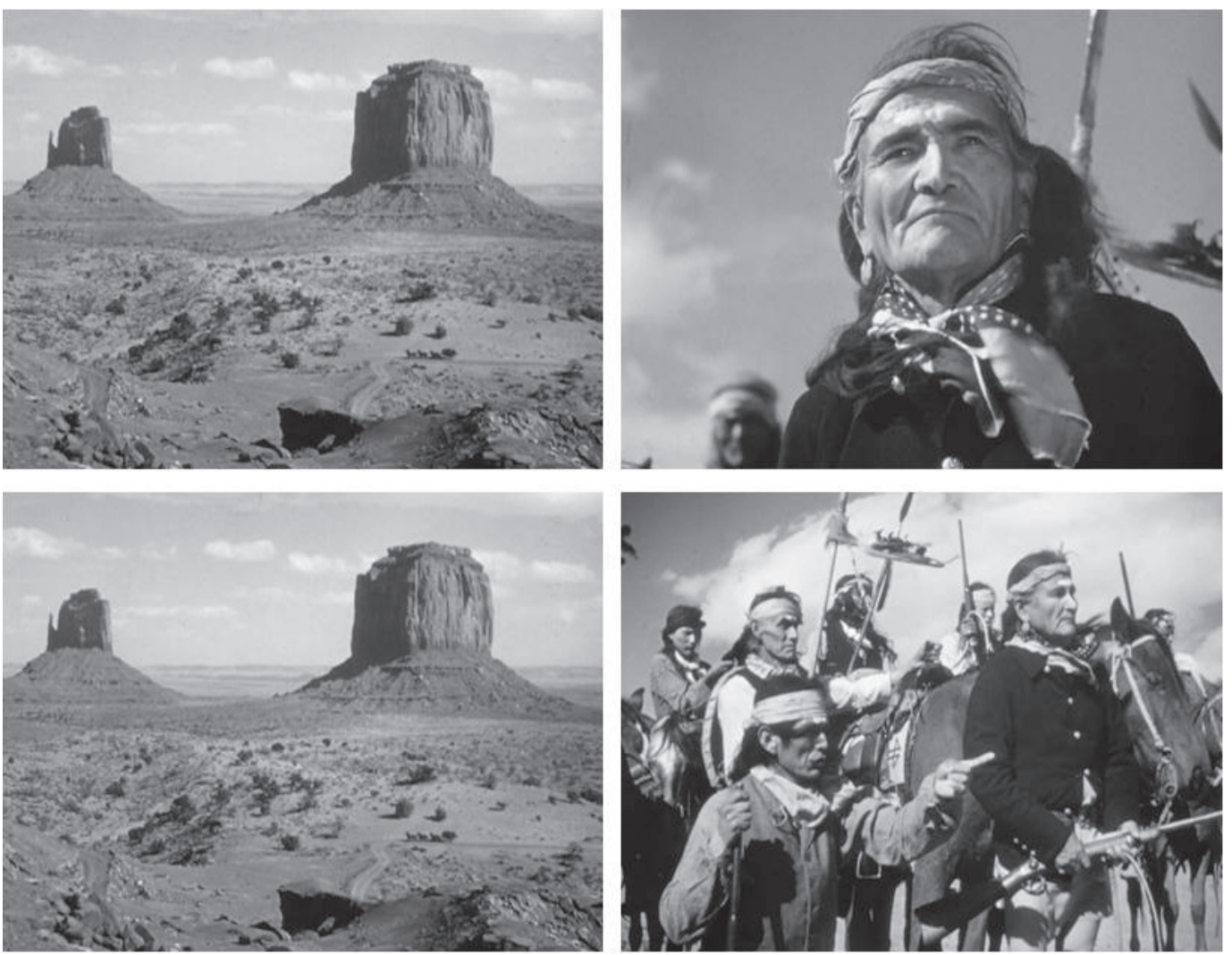

¿Cómo abordar en el aula la segunda fase del proceso de alfabetización? Puesto que la respuesta a esta pregunta excede los alcances de este artículo, sugiero aquí, de pasada y solo como un ejemplo, que la continuación del ejercicio de lectura cinematográfica de $\mathrm{La}$ diligencia (1939) podría ser la ejecución de una práctica en la que los alumnos graben o editen una pequeña secuencia del enfrentamiento o la persecución entre dos personajes, 
pero echando mano de los diferentes tamaños de plano y sus funciones narrativas, descriptivas o dramáticas, para producir con ello una mayor empatía del espectador por uno u otro personaje. Este ejercicio complementaría, por ejemplo, el proceso de alfabetización audiovisual con respecto a uno de los tantos aspectos que conforman el lenguaje audiovisual: la relación entre los tamaños de plano y la ideología.

Es importante decir que la fase de enseñanza de la escritura audiovisual ha sido considerada casi invariablemente como materia exclusiva de las escuelas de cine o comunicación. Considero que esto es un grave error y que, como la forma de comunicación más difundida actualmente, la escritura audiovisual debe ser parte de la formación de todo alumno del sistema educativo mexicano.

Habiendo hecho esta aclaración, y para cerrar al ejercicio de La diligencia (1939), se puede decir que un espectador que conciba el cine como ventana asumirá que las diferencias entre apaches y pasajeros son naturales y que la cámara no hace más que dar cuenta de ellas tal y como son. En cambio, un espectador que conciba el cine como marco verá en las diferencias entre apaches y pasajeros una construcción que implica una mirada colonialista del oeste.

Hasta aquí el ejercicio de La diligencia (1939). Retomo ahora el hilo de reflexión en torno a las teorías del cine que iniciamos con el análisis de High Anxiety (1977). Mientras la primera parte de la secuencia permite a los alumnos pensar la pantalla como ventana, la segunda posibilita que la piensen como marco. Así, una misma secuencia da pie para discutir en el aula dos formas aparentemente irreconciliables de teorizar el cine: realismo y formalismo. No obstante, el uso de secuencias permite la enseñanza de muchas otras aproximaciones teóricas al cine. Veamos otro ejemplo.

\section{Neoformalismo, cognitivismo y postestructuralismo: tres estudios de caso}

Un hombre camina por la sala de un museo donde se exhibe la obra pictórica de Vincent Van Gogh. El hombre pasa delante del Puente Langlois con lavanderas (1888), pero sigue avanzando hasta que algo lo hace regresar y detenerse a observar esa pintura más detenidamente. El emplazamiento de la cámara muestra al hombre de espaldas, que mira la pintura en su marco. Detengo la secuencia y pregunto a mis alumnos qué metáfora del cine se tematiza en este fragmento. Opinan que se refiere a la pantalla como marco. Dejo correr de nuevo la secuencia. Un corte directo permite un acercamiento abrupto a la pintura que ahora ocupa el total de la pantalla. Detengo de nuevo la secuencia y les repito la pregunta: ¿qué metáfora del cine se tematiza en este momento? Coinciden en que al desaparecer el marco ocurre lo inverso a lo que sucede en la secuencia de High Anxiety (1977), pues aquí se pasa de la metáfora del cine como marco a la del cine como ventana al mundo. Dejo correr nuevamente el video y lo que pasa a continuación parece confirmar la opinión de mis alumnos: la pintura, estática, cobra vida, las lavanderas junto al río y la carreta tirada por caballos se animan.

Pero entonces ocurre algo desconcertante: por el lado izquierdo del cuadro entra el hombre que miraba la pintura en el museo y comienza a caminar en profundidad hacia las lavanderas. Hago una nueva pausa a la secuencia, pero hago la misma pregunta: ¿qué metáfora del cine se tematiza en este momento? Mis alumnos reflexionan por unos momentos. Alguno tímidamente sugiere que la película funciona como una puerta. En efecto, a partir de este instante el espectador aparece en escena ya no como el ojo incorpóreo del testigo 
pasivo o del voyeur, sino como una corporalidad que entra física y metafóricamente en la historia. La pantalla no es ya ni la ventana ni el marco que permiten mirar a distancia, sino un umbral que posibilita el acceso del espectador a la diégesis ${ }^{12}$.

Esta secuencia, que corresponde al inicio del episodio "Cuervos" de Los sueños de Akira Kurosawa (1990), ofrece la oportunidad de introducir en el salón de clases otras teorías del cine. De acuerdo con Elsaesser y Hagener (2015), la metáfora de la pantalla como umbral que se tematiza en este metraje es sostén de las teorías narrativas neoformalistas, cognitivistas y posestructuralistas ${ }^{13}$ que "conceptualizan la experiencia cinematográfica como la entrada en otro mundo" (p. 54) y que se preguntan por los recursos narrativos que hacen que el espectador se sumerja en la película a través de la proyección e incorpore el mundo fílmico a sí mismo a través de la identificación.

Para dichos autores, la metáfora del umbral implica que las pantallas son "membranas (semipermeables) a través de las cuales pasa o se detiene algo" (p. 55), "un lugar de tránsito entre el espectador y el acontecimiento imaginario" (p. 58). En la película La invención de Hugo (2011), por ejemplo, George Méliès y su esposa entran a una carpa en la que se está presentando el cinematógrafo de los hermanos Lumière. Como parte del programa, los asistentes están viendo La llegada de un tren a la ciudad (Lumière \& Lumière, 1896). La perspectiva oblicua con la que está filmada la escena muestra un tren que aumenta dramáticamente su tamaño conforme se aproxima a la cámara que está emplazada frente a él. Cuando el tren rompe la cuarta pared, los espectadores, asustados, se agachan para evitar que el ferrocarril los arrolle.

Después de ver esta secuencia, pregunto a mis alumnos si creen que los primeros espectadores de esta vista reaccionaron de esa manera durante la proyección, pues hay un debate aún abierto respecto a la veracidad de la anécdota. La mayoría cree que ocurrió así. Entonces agrego dos preguntas: “¿Qué creen que pensarían de esta reacción los que consideran la pantalla cinematográfica como una ventana? ¿Y los que la consideran un marco?”. La discusión permite concluir que aquellos que entienden la pantalla como marco - constructivistas y formalistas - podrían ver en la reacción "ingenua" del espectador una negación de la película como construcción; mientras que aquellos que conciben la pantalla como ventana al mundo podrían entender la reacción como la consecuencia de la desaparición de la distancia que mantenía seguro al espectador-testigo.

Entonces les propongo que pensemos la secuencia a partir de la metáfora de la pantalla como umbral. Desde esta perspectiva, detrás de la reacción de los espectadores subyace la intuición de que la pantalla funciona no solo como un umbral que permite al espectador la entrada al mundo de la película, sino como una frontera o una membrana que posibilita el desbordamiento de la película y su invasión del mundo del espectador.

Cuando les muestro, finalmente, la secuencia de Super Fantozzi (1986) en que se narra la llegada a Italia del cinematógrafo, todos mis alumnos se identifican ya con el protagonista que, al ver a todos en la sala asustados cuando el tren avanza hacia ellos, intenta

12 El término diégesis se refiere al universo construido por la película.

13 Para profundizar en las teorías neoformalistas, cognitivistas y postestructuralistas, consultar los textos de Morin (2001), Genette (1998, 2001), Thompson (1988), Bordwell (1996), Branigan (1992), Bellour (1979), Heath (1975a, 1975b, 1981) y MacCabe (1985). 
tranquilizarlos diciendo: “¡Pero si es todo falso! ¡Es todo ficción! ¿No ven que es una simple ilusión óptica?”. Todos, sin embargo, huyen de la sala. Él, que entiende el cine como marco, como mis alumnos, permanece con los brazos abiertos frente a la pantalla sin comprender qué es lo que asusta a los demás. Interrumpo de nuevo la proyección y hago la pregunta con la que inicié la clase: ¿qué pasará ahora? Por primera vez, mis alumnos no parecen tener una respuesta. Corro la secuencia. Un corte directo nos muestra, en plano general, el exterior del local. El muro es atravesado por el tren que avanza por la calle llevando incrustado al frente de la máquina el cuerpo del protagonista. Todos en el aula ríen. La secuencia permite discutir más ampliamente la manera en que la realidad fílmica permea nuestra realidad extrafílmica, y nos arrolla a veces.

\section{Conclusiones}

La alfabetización audiovisual es indispensable para el desarrollo integral de las personas en una sociedad tan audiovisualmente mediatizada comola nuestra. En México, sin embargo, falta mucho para que la alfabetización audiovisual sea considerada parte fundamental de las políticas culturales y de los programas educativos, en parte debido a la manera en que se ha concebido el cine como una ventana transparente al mundo que el espectador ve y comprende de manera "innata". Es fundamental, entonces, propiciar la reflexión del espectador respecto a la postura que asume al ver un filme y el trasfondo teórico que esta postura implica, lo que es, sin duda, el primer paso hacia el alfabetismo audiovisual del espectador.

En este trabajo propongo, a partir de la experiencia docente en el aula, que el análisis de secuencias cinematográficas - microanálisis fílmico- es una herramienta pedagógica efectiva para detonar dicha reflexión y que el microanálisis cinematográfico puede ser la piedra angular de la enseñanza de la teoría del cine dirigida a alumnos de licenciatura y de posgrado y ser la base para detonar procesos de alfabetización al interior de las aulas universitarias.

El uso pedagógico de dinámicas para la alfabetización audiovisual a partir del análisis de secuencias tiene varias ventajas sobre la utilización de filmes completos. Por un lado, la proyección de secuencias requiere mucho menos tiempo de la clase, lo que posibilita dedicar buena parte de la sesión al trabajo de análisis, discusión y aprendizaje alrededor del material audiovisual. Por otra parte, trabajar con secuencias permite al alumno concentrar su atención en un fragmento específico del filme y no perderse en la totalidad de la película. Puesto que las secuencias pueden visionarse muchas veces, su uso favorece que la mirada del espectador común se vuelva poco a poco analítica. Finalmente, el microanálisis fílmico permite al docente centrar sus esfuerzos pedagógicos en algún concepto -teórico o referente al lenguaje cinematográfico- para trabajarlo más focal y profundamente a través de una secuencia que, finalmente, tiene el potencial de todo material audiovisual de ser un recurso mnemotécnico para el alumno y de detonar un aprendizaje significativo.

El diseño de estrategias didácticas en torno al microanálisis de secuencias que aquí formulo es una propuesta pedagógica innovadora para la enseñanza de la teoría del cine, pues invierte el habitual proceso de aprendizaje a partir de los textos teóricos. Lo que en este trabajo planteo es estudiar la teoría del cine a partir del propio cine y su análisis. Se trata de un proceso alfabetizador casuístico e inductivo, pues con base en estudios de caso 
—-secuencias-, el espectador produce, a partir de sus habilidades analíticas, reflexiones teóricas que sientan las bases de su alfabetismo audiovisual. Ello tiene numerosas ventajas respecto al modelo tradicional, pues el saber se construye a partir de la reflexión y la participación analítica activa de los alumnos universitarios, lo cual produce conocimientos mucho más memorables y significativos.

\section{Referencias}

Arnheim, R. (1986). El cine como arte. Paidós.

Bálasz, B. (2013). El hombre visible o la cultura del cine. Cuenco de Plata.

Barsam, R. (2010). Looking at Movies. An Introduction to Film. Norton.

Bazin, A. (1990). ¿Qué es el cine? Rialp.

Bellour, R. (1979). Lanalyse du film. Albatros.

Bordwell, D. (1996). La narración en el cine de ficción. Paidós.

Bordwell, D. (1997). On the History of Film Style. Harvard University Press.

Bordwell, D., \& Thompson, K. (1995). El arte cinematográfico. Una introducción. Paidós.

Branigan, E. (1992). Narrative Comprehension and Film. Routledge.

Brecht, B., \& Bentley, E. (1961). On Chinese Acting. The Tulane Drama Review, 6(1), 130 136. https://doi.org/10.2307/1125011.

Brooks, M. (Director). (1977). High Anxiety [Las ansiedades del Dr. Mel Brooks] [Película]. Crossbow Productions.

Burch, N. (1985). Praxis del cine. Fundamentos.

Casetti, F. (2010). Teorías del cine. Cátedra.

D’Agostini, F. (2000). Analíticos y continentales: guía de la filosofía de los últimos treinta años. Cátedra.

Eisenstein, S. (2001). Hacia una teoría del montaje. Grupo Planeta.

Elsaesser, T., \& Hagener, M. (2015). Introducción a la teoría del cine. UAM Ediciones.

Ferrés, J. (2006). La competencia en comunicación audiovisual: propuesta articulada de dimensiones e indicadores. Quaderns del CAC, 25, 9-18.

Ford, J. (Director). (1939). Stagecoach [La diligencia] [Película]. Walter Wanger Productions.

Genette, G. (1972). Figuras III. Lumen.

Genette, G. (1998). Nuevo discurso del relato. Cátedra.

Genette, G. (2001). Umbrales. Siglo XXI.

Heath, S. (1975a). Film and System: Terms of Analysis. Part I. Screen, 16(1), 7-77. https:// doi.org/10.1093/screen/16.1.7

Heath, S. (1975b). Film and System: Terms of Analysis. Part II. Screen, 16(2), 91-113. https:// doi.org/10.1093/screen/16.2.91 
Heath, S. (1981). Questions of Cinema. Macmillan.

Jullier, L. (2019). L’analyse de séquences. Armand Colin.

Jullier, L., \& Michel, M. (2007). Lire les images de cinéma. Larousse.

Konisberg, I. (2004). Diccionario técnico Akal de cine. Ediciones Akal.

Kracauer, S. (1960). Teoría del cine. La redención de la realidad física. Paidós.

Kurosawa, A. (Director). (1990). Los sueños de Akira Kurosawa [Yume] [Película]. Warner Bros; Akira Kurosawa USA.

Lipovetsky, G. (2009). La pantalla global. Cultura mediática y cine en la era hipermoderna. Anagrama.

Lumière, A. \& Lumière, L. (Directores). (1896). Larrivée d’un train à La Ciotat [La llegada de un tren a la ciudad] [Película]. Lumière.

MacCabe, C. (1985). Tracking the Signifier. Theoretical Essays: Film, Linguistics, Literature. University of Minnesota Press.

Mascelli, J. (2012). Las cinco claves de la cinematografía. CUEC; UNAM.

Monaco, J. (2009). How to Read a Film: Movies, Media, and Beyond. Oxford University Press.

Morin, E. (2001). El cine o el hombre imaginario. Paidós.

ONU. (1948). Declaración Universal de los Derechos Humanos. https://www.un.org/es/ universal-declaration-human-rights/

Parenti, N. (Director). (1986). Super Fantozzi [Película]. Scena Film; Reteitalia.

Scorsese, M. (Director). (2011). La invención de Hugo [Hugo] [Película]. Paramount Pictures; GK Films; Infinitum Nihil; Janimation.

Thompson, K. (1988). Breaking the Glass Armour: Neoformalist Film Analysis. Princeton University Press.

Vanoye, F., \& Goliot-Lété, A. (2008). Principios de análisis cinematográfico. Abada Editores.

Zavala, L. (2000). La verdad sobre la verdad: elementos para construir y deconstruir la verdad. La Palabra y El Hombre, 114, 83-91.

Zavala, L. (2004). Metaficción en literatura y cine. En B. Mariscal, B. López, \& M. Miaja (Eds.), Actas del XV Congreso de la Asociación Internacional de Hispanistas (pp. 741-749). Centro Virtual Cervantes. https://cvc.cervantes.es/literatura/aih/pdf/15/aih_15_3_058. pdf

Zavala, L. (2012). La representación de la violencia física en cine de ficción. Versión. Estudios de Comunicación y Política, 29, 1-13. https://versionojs.xoc.uam.mx/index.php/version/ article/view/489

Zunzunegui, S. (1996). La mirada cercana. Microanálisis fílmico. Paidós. 